\title{
Mössbauer Spectra of Substituted Pentacyanoferrates(II) Containing Monoprotonated Diamines or Nitrogenated Heterocycles
}

\author{
Pedro J. Aymonino \\ Cátedra de Química Inorgánica, Facultad de Ciencias Exactas, Universidad Nacional de La Plata ${ }^{1}$ \\ Miguel A. Blesa \\ Departamento de Fisicoquímica, Facultad de Farmacia y Bioquímica, Universidad de Buenos Aires \\ José A. Olabe \\ Departamento de Política Científica y Tecnológica, Universidad Nacional de Luján \\ and \\ Enrique Frank \\ Comisión Nacional de Energía Atómica, Buenos Aires ${ }^{1}$ \\ (Z. Naturforsch. 31 b, 1532-1535 [1976]; received July 28, 1976)
}

Mössbauer parameters, Pentacyanoferrates(II), Diamines, Heterocycles

\begin{abstract}
Mössbauer parameters (IS and NQS) for a series of hydrated sodium pentacyano-L ferrates(II) ( $\mathrm{L}=$ monoprotonated diamines or nitrogenated heterocycles) are presented. Results are discussed in terms of electronic properties of the ligands. A tentative distinction between $\sigma$-and $\pi$-bonding effects is shown and comparisons are made with previous results reported for related substances.
\end{abstract}

Weinofen ${ }^{2}$ and Toma et al. ${ }^{3}$ have reported the results of the Mössbauer study of a series of iron(II) pentacyanoferrates. In the present communication we wish to report further data on related compounds in order to discuss their spectral properties and to complement previous work.

The room temperature spectra of the studied pentacyanoferrate(II) salts consist of symmetric doublets, except for the nicotinamide complex which gives an asymmetric doublet with an intensity ratio of lower velocity line to higher velocity line of the order of 0.7. Both the isomer shift and the quadrupole splitting are related to the bonding properties of the ligands and it is interesting to attempt an estimation of the relative $\sigma$ and $\pi$ contributions. Stronger $\sigma$ donors increase the $\mathrm{s}$ electron density at the iron nucleus, and should therefore give rise to smaller isomer shifts; stronger $\pi$ acceptors produce the same effect through the

Requests for reprints should be sent to Prof. Dr. P. J. Aymonino, Cátedra de Química Inorgánica, Facultad de Ciencias Exactas, Universidad Nacional de La Plata, Calle 47 Esquina 115, La Plata, Argentina. deshielding of the $\mathrm{s}$ electron density at the iron nucleus. Thus, smaller isomer shifts should reflect stronger bonds. Within the series of substituted pentacyanoferrates(II) with pyridines and pyrazines as the sixth ligand, it is known that the strength of the $\mathrm{Fe}-\mathrm{N}$ bond, as measured by the rate constants and activation enthalpies for the release of the ligands from the complexes in water, is not very sensitive to changes in the ligand, and this comes about through an extensive cancellation of the changes in $\sigma$ and $\pi$ bond strength 4 .

The quadrupole splitting resulting from the field gradient acting at the $\mathrm{Fe}$ nucleus should also be governed by $\sigma$ and $\pi$ effects, but in this case the worst $\sigma$ donors and the better $\pi$ acceptors bring about a larger asymmetry of the electronic cloud, creating thus a larger splitting 5 .

Thus in the series of heterocyclic ligands we are dealing with, both $\sigma$ and $\pi$ effects are operating while in the series of complexes containing monoprotonated diamines no $\pi$-bonding is expected and therefore the importance of changes in $\sigma$ bonding could be made evident. 
Toma et al. have reported data on methylpyrazinium $\left(\mathrm{MP}_{z}{ }^{+}\right)$, pyrazine carboxylate $\left(\mathrm{P}_{z} \mathrm{CO}_{2}{ }^{-}\right)$ and pyridine [py] complexes ${ }^{3}$. In the present work, we submit data on the pentacyanoferrate(II) complexes of pyrazine mono $\mathrm{N}$-oxide $\left(\mathrm{P}_{z} \mathrm{O}\right)$, isonicotinic acid hydrazide (INAH), 4-picoline (pic), nicotinamide (NA) and the members of a series of monoprotonated diamine ions: $\mathrm{N}_{2} \mathrm{H}_{5}{ }^{+}, \mathrm{H}_{2} \mathrm{~N}\left(\mathrm{CH}_{2}\right)_{3} \mathrm{NH}_{3}{ }^{+}$ $\left(\mathrm{pnH}^{+}\right), \mathrm{H}_{2} \mathrm{~N}\left(\mathrm{CH}_{2}\right)_{6} \mathrm{NH}_{3}{ }^{+}\left(\right.$henH $\left.{ }^{+}\right)$and piperazinium $\left(\mathrm{pipH}^{+}\right)$. Previously, we had reported data on the py and $\mathrm{H}_{2} \mathrm{~N}\left(\mathrm{CH}_{2}\right)_{2} \mathrm{NH}_{3}{ }^{+}\left(\mathrm{enH}^{+}\right)$complexes ${ }^{6,7}$; in this previous work, possible trends in quadrupole splitting were probably obscured by the small number and very diverse nature of the ligands studied.

\section{Experimental}

The sodium salts of the various compounds were prepared from the corresponding free ligand by either one of the following techniques: a) direct reaction with sodium nitroprusside in methanol, or b) substitution for $\mathrm{NH}_{3}$ in $\mathrm{Na}_{3}\left[\mathrm{Fe}(\mathrm{CN})_{5} \mathrm{NH}_{3}\right] \cdot 3 \mathrm{H}_{2} \mathrm{O}$ in a methanolic slurry. For further details see for example references 6 and 7 . Several of the compounds had not been described previously; they were characterized by UV-VIS, IR, chemical analysis and TGA; further details will be published in due course.

Mössbauer spectra were obtained at room temperature on an Elron spectrometer operated in the constant acceleration mode. Powdered samples of the complex salts were placed in acrylic disks containing $c a .5 \mathrm{mg} / \mathrm{cm}^{2}$ of the absorbing nuclide. The source was $c a .20 \mathrm{mC}$ of ${ }^{57} \mathrm{Co}$ in a Pd matrix. Calibration was performed with a thin sodium nitroprusside/potassium hexacyanoferrate(II) mixture, before and after each run. Statistics was at least $6 \times 10^{5}$ counts per channel and the weakest absorption was of the order of $2 \%$. The data were fitted with a least squares fitting program based on the Gauss-Newton method, with different constraints. Typical $\chi^{2}$ values of the reported fits were in the range $240-320$, for 252 points-spectra with 5 to 7 adjustable parameters. Both peaks of the doublets were always of nearly the same height (except where noted) and not more than $0.320 \mathrm{~mm} / \mathrm{s}$ wide, although for most of the samples this value was around $0.280 \mathrm{~mm} / \mathrm{s}$. Impurity level was small except for INAH, which gave higher $\chi^{2}$ values when the sample was somewhat old. $\chi^{2}$ values were reduced in this case to the previously mentioned level when introducing a second quadrupole split doublet with intensities up to $10 \%$ of the main peaks.

Table I. Isomer shifts, quadrupole splittings and related data for $\mathrm{Na}_{2}\left[\mathrm{Fe}(\mathrm{CN})_{5} \mathrm{~L}\right] \cdot x \mathrm{H}_{2} \mathrm{O}$ at room temperature $(\mathrm{L}=$ protonated diamines $)$.

\begin{tabular}{|c|c|c|c|c|}
\hline Ligand & $\begin{array}{l}\text { Isomer shift }{ }^{\mathrm{a}} \\
(\mathrm{mm} / \mathrm{s}) \pm 0.015\end{array}$ & $\begin{array}{l}\text { Quadrupole splitting } \\
(\mathrm{mm} / \mathrm{s}) \pm 0.008\end{array}$ & $\begin{array}{l}\mathrm{pK}_{\mathrm{a}} \\
\left(\mathrm{H}_{2} \mathrm{~L}^{2+}\right)\end{array}$ & Ref. \\
\hline $\mathrm{N}_{2} \mathrm{H}_{5}+$ & 0.280 & 0.735 & -1 & this work, 8 \\
\hline $\mathrm{enH}^{+}$ & 0.273 & 0.787 & 7.6 & $6,7,9$ \\
\hline $\mathrm{pnH}^{+}$ & 0.286 & 0.756 & 9.0 & this work, 9 \\
\hline henH $\mathrm{H}^{+}$ & 0.288 & 0.788 & 10.8 & this work, 9 \\
\hline $\mathrm{pipH}^{+}$ & 0.297 & 0.995 & 5.6 & this work, 9 \\
\hline
\end{tabular}

a Standard: sodium nitroprusside at room temperature.

Table II. Isomer shifts, quadrupole splittings and related data for $\mathrm{Na}_{3}\left[\mathrm{Fe}(\mathrm{CN})_{5} \mathrm{~L}\right] \cdot x \mathrm{H}_{2} \mathrm{O}$ at room temperature $(\mathrm{L}=\text { heterocyclic ligands })^{\mathrm{a}}$.

\begin{tabular}{lllll}
\hline Ligand & $\begin{array}{l}\text { Isomer shift } \\
(\mathrm{mm} / \mathrm{s}) \pm 0.015\end{array}$ & $\begin{array}{l}\text { Quadrupole splitting } \\
(\mathrm{mm} / \mathrm{s}) \pm 0.008\end{array}$ & $\begin{array}{l}\lambda_{\max } \\
(\mathrm{nm})\end{array}$ & $\begin{array}{c}\text { Ref. } \\
\text { (n) }\end{array}$ \\
\hline $\mathrm{MP}_{z^{+}}$ & 0.241 & 1.10 & 655 & 3,4 \\
$\mathrm{P}_{z} \mathrm{O}$ & 0.265 & 0.966 & 505 & this work \\
$\mathrm{P}_{z} \mathrm{CO}_{2}{ }^{-}$ & 0.261 & 0.96 & $4^{\mathrm{c}}$ & 3 \\
$\mathrm{INAH}$ & 0.256 & 0.890 & $4^{\mathrm{d}}$ & this work \\
$\mathrm{NA}$ & 0.256 & 0.883 & 385 & this work \\
pic & 0.260 & 0.830 & 358 & this work, \\
py & $0.284^{\mathrm{e}}$ & $0.784^{\mathrm{e}}$ & 365 & this work, \\
\hline
\end{tabular}

a Data from Ref. ${ }^{3}$, originally given at $77 \mathrm{~K}$ have been corrected to room temperature assuming dIS/dT $=$ $-3.6 \times 10^{-4} \mathrm{~mm} / \mathrm{sK}$ and $\mathrm{dQS} / \mathrm{dT}=0$, as suggested by WeiHoFEN's results for similar compounds ${ }^{2}$.

b Standard: sodium nitroprusside at room temperature.

c H. E. Toma, J. Inorg. Nucl. Chem. 37, 785 [1975].

d M. A. Blesa, P. J. Morando, I. Funai, P. J. Aymonino, J. A. Olabe, and G. Ellenrieder, J. Chem. Soc. Dalton, in press.

e These are revised values of the figures reported in ${ }^{6}$. 


\section{Results and Discussion}

Tables I and II contain the results of our measurements, together with data from other sources. For purposes of comparison the data from reference ${ }^{3}$ which were measured at $77 \mathrm{~K}$ were corrected to room temperature. The temperature dependence of the IS is due to the second order Doppler shift, originated in the lattice properties and related to the Debye temperature, whereas for the quadrupole splitting it stems from the different population of the electronic levels. For low spin $\mathrm{Fe}(\mathrm{II})$ complexes the temperature dependence of $\mathrm{QS}$ is in general negligible, as confirmed by WeIHOFEN's results ${ }^{2}$, which are used in Table II as explained.

\section{a) Protonated diamines}

The series of protonated diamines was specially interesting in view of the wide range of $\mathrm{pK}_{\mathrm{a}}$ values covered by the ligands (see Table I). The constancy found for the isomer shift $(0.27-0.30 \mathrm{~mm} / \mathrm{s})$ is remarkable; interestingly, the same range of IS values has been reported for monoamines ${ }^{2}$. Therefore, the IS does not seem to be sensitive to drastic changes in the basicity of the amines and to the presence of the positive charge borne by the monoprotonated diamines. A constancy of the amount of $\sigma$-donation from the amines to the iron nucleus is precluded by the kinetic results which show a measurable dependence of the dissociation constants when basicity ${ }^{10}$ or charge effects ${ }^{11}$ are operating. It is to be noted however that the correlation predicted by the equation $\log \mathrm{k}_{\mathrm{d}}=\mathrm{A}+\mathrm{B} \mathrm{pK}_{\mathrm{a}}$ (cf. 10) $\left(\mathrm{pK}_{\mathrm{a}}\right.$ refers to the conjugated acid of the ligand) fails when applied to a more extensive series of monoamines ${ }^{12}$.

Our data provide a good experimental ground to previous suggestions ${ }^{13}$ that the IS in prussides is governed solely by the amount of $\pi$ donation. Changes in the nature of the sixth ligand in $\left[\mathrm{Fe}(\mathrm{CN})_{5} \mathrm{~L}\right]^{n-}$ are reflected in the IS only if $\mathrm{L}$ is a $\pi$ acceptor; changes in $\sigma$-bonding are to be considered minor effects, especially taking into account that $\mathrm{d}^{2} \mathrm{sp}^{3}$ hybrids with small s-character are involved in the bond formation. The lack of a clear influence of the charge borne by the free end of the protonated diamines is, however, somewhat surprising, as various effects could be expected, giving rise to changes in the electronic density on the iron nucleus.
NQS data for the complexes of the monoprotonated diamines fall also in the range reported for monoamines $(0.7-0.9 \mathrm{~mm} / \mathrm{s})$, with the exception of $\mathrm{pipH}^{+}(0.995 \mathrm{~mm} / \mathrm{s})$, and as the IS it seems to be also constant, although the scatter of the results is somewhat higher in this case. The high value found for $\mathrm{pipH}^{+}$is in fact not too far from the NQS value reported for morpholine $(0.901 \mathrm{~mm} / \mathrm{s})^{2}$.

\section{b) Heterocyclic ligands}

The IS values for these ligands lie close to $0.26 \mathrm{~mm} / \mathrm{s}$, with the exception of $\mathrm{MP}_{z}{ }^{+}$and the presently reported value for the py complex (this figure corrects the value reported in Ref.6). $\pi$-bonding is reflected in the smaller IS values as compared with monoamines and protonated diamines. $\mathrm{MP}_{z}{ }^{+}$ has been shown to be a very strong $\pi$ acceptor ${ }^{3,4}$ (it is not obviously true, however, that the temperature dependence of the IS for the $\mathrm{MP}_{z}{ }^{+}$complex should be the same as in similar complexes bearing a different charge, as was assumed in our estimation). Unsubstituted pyridine, on its part, seems to be the worst $\pi$ acceptor in the series, IS shifts for the other members of the series being practically not sensitive to the (small) differences expected in the $\pi$-bonding strength.

The NQS sequence, however, does reflect clearly the decrease in $\pi$-back donation as we go down the table. The ordering of $\pi$ acceptor character has been established on the basis of a series of properties of the ligands ${ }^{4}$, in particular the position of the intense metal-to-ligand charge transfer band in the visible spectrum. The values for $\lambda_{\max }$ for this transition are also shown in Table II. The expected correlation between this parameter and NQS is clearly seen; py seems to be an exception, because its complex shows a remarkably low NQS value.

For a series of ligands covering a wider range of $\pi$ bond strengths, Toma et al. ${ }^{3}$ did not attempt to separate $\sigma$ and $\pi$ contributions to the quadrupole splittings. However, an estimate can be obtained for our series of heterocyclic ligands, using the results obtained with the series of diamines, i.e. the relative constancy of the quadrupole splitting when the $\mathrm{pK}_{\mathrm{a}}$ of the ligand changes. Taking as a rough guide a value of $0.75 \mathrm{~mm} / \mathrm{s}$ for ligands where no $\pi$ return can be operative, the difference with the actual values included in Table II could therefore be ascribed to $\pi$ effects. 
To the Consejo Nacional de Investigaciones Cientificas y Técnicas for research funds. E. F. is

1 Member of the Carrera del Investigador del Consejo Nacional de Investigaciones Científicas y Técnicas. 2 U. Weinofen, Z. Naturforsch. 27 a, 565 [1972].

3 H. E. Toma, E. Giesbrecht, J. M. Malin, and E. FluCK, Inorg. Chim. Acta 14, 11 [1975].

${ }^{4} \mathrm{H}$. E. Toma and J. M. Malin, Inorg. Chem. 12, 1039,2080 [1973].

5 G. M. Bancroft and R. M. Platt, Adv. Inorg. Chem. and Radiochem. 15, 59 [1972].

6 J. A. Olabe and P. J. Aymonino, J. Inorg. Nucl. Chem. 38, 225 [1976].

7 J.A. Olabe and P.J.Aymonino, ibid. 36, I 221 [1974].

8 F. A. Cotton and G. Wilkinson, "Advanced Inorganic Chemistry," Third Edition, p. 359, Interscience, N. Y. 1972. specially indebted to the "Fundación Sauberán" and "Fundación Esso" for financial support.

9 "Handbook of Chemistry \& Physics," 51st. Edition, R. C. West, Editor, The Chemical Rubber Co., 1970-71. Data given refer to various temperatures, ranging from 0 to $25^{\circ} \mathrm{C}$, but this difference is not important for the present purposes.

10 H. E. Toma and J. M. MALIN, Inorg. Chem. 13, 1772 [1974].

11 M. A. Blesa, J. A. Olabe, and P. J. Aymonino, J. Chem. Soc. Dalton 1976, 1196.

12 N. E. Katz, P. J. Aymonino, M. A. Blesa, and J. A. Olabe, to be published.

13 E. Fluck, Adv. Inorg. Chem. and Radiochem. 6, 433 [1964]. 